Research Article

\section{Atypical manifestations of pulmonary embolism}

\section{Oscar MP Jolobe*}

Manchester Medical Society, Medical Division, Simon Building, Brunswick Street, Manchester, M13 9PL, UK

\section{Abstract}

Pulmonary embolism (PE) is an age-related disorder which is potentially fatal, but frequently misdiagnosed. However, the true prevalence of pulmonary embolism is unknown. Inaccurate estimates of PE prevalence might, in part, be attributable to underrecognition of atypical presentations of this disorder. If true prevalence is unknown, the positive predictive values of both typical and atypical symptoms and signs of PE will be unreliable. The negative predictive value of those parameters will, likewise, be unreliable. The aim of this review is to make clinicians more aware of atypical manifestations of PE, thereby increasing the likelihood of correct diagnosis and, hence, ascertainment of the true prevalence of PE. The range of atypical manifestations was explored by a literature search, using MEDLINE from 1946 to February 2019, and EMBASE, from 1947 to February 2019, and Pubmed, from February 2014 to February 2019, using the search terms atypical, uncommon, unusual, pulmonary embolism, lung embolism, pulmonary thromboembolism.

This search revealed atypical presenting features such as non pleuritic retrosternal pain, abdominal pain, atypical breathing patterns, pulmonary oedema, Dressler's syndrome, atypical radiographic manifestations, atypical electrocardiographic features, manifestations associated with oxygen saturation of $95 \%$ or more, coexistence of acute myocardial infarction and pulmonary embolism, coexistence of thoracic aortic dissection and pulmonary embolism, neurological manifestations other than stroke, paradoxical embolism, acute venous thrombosis of atypical location, and pulmonary embolism with normal D-dimer levels.

\section{More Information}

\author{
*Address for Correspondence: Oscar MP \\ Jolobe, MRCP, Manchester Medical Society, \\ Medical Division, Simon Building, Brunswick \\ Street, Manchester, M13 9PL, UK \\ Tel: 441619006887 ; \\ Email:oscarjolobe@yahoo.co.uk
}

\section{Submitted: 17 February 2020 \\ Approved: 15 April 2020 \\ Published: 16 April 2020}

How to cite this article: Jolobe OPM. Atypical manifestations of pulmonary embolism. Arch Vas Med. 2020; 4: 008-018.

\section{DOI: 10.29328/journal.avm.1001012}

Copyright: (c) 2020 Jolobe OPM. This is an open access article distributed under the Creative Commons Attribution License, which permits unrestricted use, distribution, and reproduction in any medium, provided the original work is properly cited.

Keywords: Pulmonary; Embolism; Atypical; Manifestations

Check for updates

OPEN ACCESS

\section{Introduction}

Clinical decision rules (CDRs) are the building blocks for clinical decision making in pulmonary embolism (PE). They can be used to rule in PE (as in the Wells Rule) or to rule out PE (as in the PERC Rule). In the original Wells formula typical manifestations of PE were deemed to be 2 or more respiratory points (ie new-onset dyspnoea or worsening chronic dyspnoea, pleuritic chest pain, chest pain that is nonretrosternal and nonpleuritic, an arterial oxygen saturation less than $92 \%$ while breathing room air that corrects with oxygen supplementation less than $40 \%$, hemoptysis, and pleural rub), and leg symptoms. Other typical manifestations include low-grade fever and results of chest radiography compatible with PE. Atypical manifestations were those that did not belong to the "typical" category [1].

In a subsequent study, Wells, et al. formulated a simplified CDR where the variables (again characterised by typicality for PE) comprised haemoptysis, heart rate > 100/minute, immobilisation or surgery in the past 4 weeks, clinical signs and symptoms of deep vein thrombosis (DVT), malignancy, and an alternative diagnosis less likely than PE. Using those variables, a total score of $>4$ signified that PE was likely [2].

The Pulmonary Embolism Rule out Criteria (PERC) was a CDR formulated to rule out PE in patients perceived to have low probability of PE, the latter on the basis of the clinician's unstructured clinical evaluation. In such patients the aim of the CDR was to rule out PE if all eight of the following criteria were fulfilled:

Age $<50$, pulse $<100 /$ minute, $\mathrm{SaO}_{2}>94 \%$, no unilateral leg swelling, no haemoptysis, no recent trauma or surgery, no prior PE or DVT, and no hormone use [3].

Strict application of PERC criteria generates a 1\% prevalence of missed PE [4]. This is rate of missed diagnosis is acceptable, given the fact that a $2 \%$ rate of missed diagnosis in the point of equipoise where subjects with a lower rate of missed diagnosis would not be benefited by diagnostic testing [5], or might even be harmed by diagnostic procedures such as computed tomography pulmonary angiography (CTPA) which pose radiation risk and risk of contrast-related renal injury [6]. 
In contrast to the proliferation of CDRs subsequent to Wells, a school of thought has emerged which posits that unstructured clinical impression (so-called "gestalt") is, at the very least, as reliable as the sole use of CDRs [7]. Vital signs such as respiratory rate (RR) and $\mathrm{SaO}_{2}$ are available both to $\mathrm{CDR}$ and to gestalt. According to one study, respiratory rate of $<21 /$ minute is associated with a $95 \%$ negative predictive value for $\mathrm{PE}$ [8]. By contrast a $\mathrm{SaO}_{2}$ of $<95 \%$ (whilst breathing room air) is associated with an Odds Ratio of 3.3 (95\% Confidence Interval 2.5 to 4.4) in favour of PE [3].

PE can, however, be totally asymptomatic even in patients who have DVT complicated by emboli located in the major pulmonary arteries [9]. The corollary is that, in one study, among 334 subjects with CTPA-validated PE, up to $75.9 \%$ of the patients with centrally located pulmonary emboli failed to achieve a "PE likely" score of $>4$. In that study there were 7 PE-related fatalities in patients with centrally located emboli, and 3 deaths among patients with segmental emboli. There were no deaths among patients with subsegmental emboli [10].

\section{Atypical manifestations of pulmonary embolism}

Typical presenting symptoms and signs usually depicted in CDRs comprise cough, haemoptysis, pleuritic chest pain, nonretrosternal non pleuritic chest pain, new onset dyspnoea, worsening chronic dyspnoea, unilateral leg swellng, and $\mathrm{SaO}_{2}$ $<95 \%[1-3,30]$. Atypical presenting symptoms and signs are those which do not belong to the typical category. Atypical manifestations can occur in isolation. Alternatively, they may occur in association with typical signs and symptoms.

\section{Retrosternal pain that is non pleuritic}

According to Wells, et al. non pleuritic retrosternal pain belongs to a category which is atypical of PE [1]. When non pleuritic retrosternal pain occurs in PE it is attributable, in some cases, to myocardial ischaemia, the latter the outcome of the combination of hypoxemia and increased cardiac work [11]. This presentation can simulate acute coronary syndrome, especially in the presence of elevation in serum troponin levels and concurrent ST segment depression and/ or T wave inversion [12]. Diagnostic confusion is compounded by the fact that PE can also present with electrocardiographic (ECG) stigmata simulating ST segment elevation myocardial infarction (STEMI) in the absence of concurrent coronary artery occlusion [13]. In the latter review of this phenomenon, the STEMI stigmata occurred most frequently in leads V1-V4, less frequently in the inferior leads II, III, and AVF, and least frequently in leads V5 and V6. The diagnosis of PE was validated by CTPA, ventilation/perfusion scintigraphy, angiography, and autopsy, in $6,2,17$, and in 8 subjects, respectively. The Wells score for PE amounted to $<2$ in $44.4 \%$ of the 27 patients in whom that parameter was measured [13].

Exceptionally, PE may coexist with acute myocardial infarction (AMI). This scenario occurs when AMI-related right ventricular mural thrombus is complicated by the occurrence of PE [14]. Conversely AMI may be the outcome of PE-related paradoxical embolism (PDE) [15].

\section{Abdominal pain}

Abdominal pain (or flank pain) may be a feature of PE under the following circumstances (Table 1).

(i) Abdominal pain may be the sole manifestation of PE.

This manifestation of PE may be a symptom of acute onset hepatic congestion attributable to PE-related right heart failure [16,17]. In other instances PE-related abdominal pain is believed to be attributable to diaphragmatic irritation resulting from lower lobe pulmonary infarct [18].

(ii) Abdominal pain which simulates abdominal pain attributable to AMI.

This scenario occurs when PE-related abdominal pain is associated with an electrocardiogram which shows ST segment elevation $[19,20]$. The differential diagnosis of this scenario includes AMI, a disorder in which a study of 94 consecutive subjects with atypical AMI documented a $11 \%$ prevalence of abdominal pain among subjects who did not have chest pain [21]. That statistic is fortuitously close to the statistic of a $12 \%$ prevalence of abdominal pain among 90 subjects with PE evaluated by Israel, et al. [22].

(iii) PE-related abdominal pain which is attributable to the underlying cause of PE.

This scenario is exemplified by ovarian vein thrombosis, a disorder which may not only be the underlying cause of abdominal pain, but also the underlying cause of PE [23].

Table 1: Pulmonary embolism-related abdominal pain.

\begin{tabular}{|c|c|c|c|c|c|c|}
\hline First author and reference & Age & Sex & RR & SaO $_{2} \%$ & Typical PE symptoms & Comments \\
\hline Al-Mane [16] & 35 & F & 27 & 98 & Hepatic congestion \\
\hline Phillipp [17] & 21 & F & NA & NA & Hepatic congestion \\
\hline Gantner [18] & 48 & M & 16 & 99 & N & Right lower lobe infarct \\
\hline Fallahi [19] & 54 & M & 20 & 92 & ST segment elevation & ST segment elevation \\
\hline Hodgkinson [20] & 20 & M & NA & NA & Y & Ovarian vein thrombosis \\
\hline Heavrin [23] & 29 & F & 16 & 100 & Y & Paradoxical splenic artery embolism \\
\hline Vavuranakis [24] & 28 & F & 31 & 80 & N & Paradoxical splenic renal and hepatic artery embolism \\
\hline Turedi [25] & 73 & F & 32 & NA & N &
\end{tabular}

KEY: M: Male; F: Female; Y: Yes; N: No; NA: Not Available 
(iv) PE - related abdominal pain attributable to paradoxical embolism.

This occurs when PE is complicated by paradoxical embolism involving, the splenic artery [24], or the splenic, renal, and hepatic arteries simultaneously [25].

Abdominal pain is most easily identifiable as being attributable to $\mathrm{PE}$ when it is associated with other symptoms of PE such as breathlessness. Diagnostic difficulty occurs when abdominal pain is the sole presenting feature of $\mathrm{PE}$, as was the case in anecdotal reports [26,27] and in $9.5 \%$ of forty two PE subjects in a retrospective study conducted in a tertiary hospital [28]. Misattribution of PE-related abdominal pain to a "surgical" cause unrelated to PE can result in inappropriate laparotomy and surgical exploration $[16,22]$.

\section{Atypical breathlessness or atypical breathing pattern}

Orthopnoea is atypical of PE. In one study orthopnoea was recorded in only $38 \%$ of $97 \mathrm{PE}$ patients who had no prior cardiopulmonary disease [29]. In 19\% of 192 PE patients in that study the other atypical feature was a rate of onset of dyspnoea which covered a number of days instead of hours [29]. In a larger study of 1,100 consecutive subjects (age range 15-94) with suspected PE(including 440 with eventual angiographically proven PE) orthopnoea occurred in only $1 \%$ of PE subjects, and was significantly ( $p=0.0001)$ less common in PE than in non PE. In that study, gradual onset PE occurred in only 3\% of PE subjects, and was, also, significantly ( $p=0.0001)$ less common in PE than in non PE [30]. According to another study, patients with gradual onset dyspnoea experience significantly $(p<0.001)$ greater delay in having a diagnosis of PE than counterparts with sudden onset dyspnea [31]. Gradual onset dyspnoea is also associated with significantly $(p<0.001)$ greater risk of acquiring a mistaken diagnosis, as shown in $186 \mathrm{PE}$ patients in whom mistaken diagnoses included bronchitis (35\%), heart failure (31\%), pneumonia (13\%), and exacerbation of COPD (8\%) [31].

Platypnoea orthodeoxia is the antithesis of orthopnoea.

The clinical hallmark of this syndrome is worsening of breathlessness and worsening of hypoxaemia on sitting up. In the context of PE, this disorder is believed to be attributable to right-to-left shunting of blood through a patent foramen ovale (PFO) as a result of PE-related increase in pulmonary artery pressure [32].

In one study wheezing which had a severity similar to acute severe asthma was an atypical presentation in eleven out of 250 patients with angiographically validated PE [33]. PE-related wheezing is commoner in patients with previous cardiopulmonary disease [34]. Furthermore, asthma, itself, is associated with an increased risk of pulmonary thromboembolism [35]. PE can also atypically present as acute unexplained exacerbation of COPD [36]. In the latter meta-analysis $68 \%$ of emboli were located in main pulmonary arteries, lobar arteries, or interlobar arteries [36].

The "voice box" syndrome is an atypical feature exemplified by a 19 year old nonsmoker woman who subsequently suffered cardiorespiratory arrest attributable to massive PE. The presenting symptom was new-onset hoarseness and sore throat, initially in the absence of breathlessness. At autopsy, the underlying cause of hoarseness proved to be compression of the recurrent laryngeal nerve by a "large thrombotic formation that completely occluded the outflow tract of the pulmonary artery" [37].

Stridor was the atypical presenting feature in a 62 year old man in whom wheezing was an associated symptom. Both symptoms resolved after treatment which included heparin and bronchodilators [38].

PE can also atypically present with hiccups, without intercurrent chest pain or dyspnea [39]. In the latter report, patient 1 had a Wells score of 1.5 , patient 2 had a Wells score of 3, and patient 3 had a Wells score of 1.5[39].

\section{Pulmonary oedema as a manifestation of pulmonary embolism}

Bilateral, non-cardiogenic pulmonary oedema has been documented as a manifestation of PE in patients aged 61 [40] and 72 , respectively [41]. Unilateral pulmonary oedema was reported in a 54 year old man in whom chest radiography also showed increased lucency in one region of the lung fields (Westermark's sign) and prominence of one of the pulmonary arteries (Palla's sign)[42].

\section{Atypical radiographic signs of PE}

Atypical features include lobar consolidation mimicking pneumonia [44]. Other atypical features include cavitation [45], pneumothorax [45], hydropneumothorax [46], pyopneumothorax [47], pneumomediastinum [48], and pulmonary oedema [40-42].

\section{Pleural effusion}

Dressler's syndrome is the association of PE with pericardial effusion [49], typically in a patient with PErelated pleural effusion. When pleural effusions occur in PE, they typically occupy $<50$ of the hemithorax. Larger pleural effusions are distinctly atypical [50]. Unusually, as well, PErelated pleural effusions may be loculated [50], potentially simulating those attributable to bacterial pneumonia, especially if associated with pulmonary opacities [50].

Pulmonary embolism with $\mathrm{SaO}_{2}$ amounting to $95 \%$ or more (breathing room air) (Table 2)

$\mathrm{A} \mathrm{SaO}_{2}$ of $95 \%$ or more is atypical of PE, both in patients with typical PE symptomatology and in those with atypical symptomatology (Table 2). 
Table 2: Pulmonary embolism with $\mathrm{SaO}_{2}$ of $95 \%$ or more.

\begin{tabular}{|c|c|c|c|c|c|c|c|c|c|c|c|c|}
\hline First author and reference & Age & Sex & $\mathbf{R R}$ & $\begin{array}{c}\mathrm{SaO}_{2} \\
\%\end{array}$ & $\begin{array}{l}\text { Typical PE } \\
\text { symptoms }\end{array}$ & Hiccups & $\begin{array}{c}\text { Abdo } \\
\text { pain }\end{array}$ & ST elevation & $\begin{array}{l}\text { Giant } \mathrm{T} \\
\text { waves }\end{array}$ & Syncope & Seizures & Comments \\
\hline Larsen [51] & 18 & $\mathrm{~F}$ & 18 & 99 & Y & $\mathrm{N}$ & $\mathrm{N}$ & $\mathrm{N}$ & $\mathrm{N}$ & $\mathrm{N}$ & $\mathrm{N}$ & Dyspneoa \\
\hline Kahanov [52] & 18 & $\mathrm{~F}$ & 28 & 99 & $\mathrm{Y}$ & $\mathrm{N}$ & $\mathrm{N}$ & $\mathrm{N}$ & $\mathrm{N}$ & $\mathrm{N}$ & $\mathrm{N}$ & Chest pain \\
\hline Durning [53] & 81 & M & 20 & 98 & $\mathrm{~N}$ & $\mathrm{Y}$ & $\mathrm{N}$ & $\mathrm{N}$ & $\mathrm{N}$ & $\mathrm{N}$ & $\mathrm{N}$ & \\
\hline Mansmann [54] & 42 & M & NA & 97 & $\mathrm{~N}$ & $\mathrm{~N}$ & Y & $\mathrm{N}$ & $\mathrm{N}$ & $\mathrm{N}$ & $\mathrm{N}$ & \\
\hline Gantner [18] & 48 & M & 16 & 99 & $\mathrm{~N}$ & $\mathrm{~N}$ & Y & $\mathrm{N}$ & $\mathrm{N}$ & $\mathrm{N}$ & $\mathrm{N}$ & \\
\hline Hosein [26] & 44 & $M$ & NA & 98 & $\mathrm{~N}$ & $\mathrm{~N}$ & $\mathrm{Y}$ & $\mathrm{N}$ & $\mathrm{N}$ & $\mathrm{N}$ & $\mathrm{N}$ & \\
\hline Rehman [27] & 53 & M & 22 & 96 & $\mathrm{~N}$ & $\mathrm{~N}$ & $\mathrm{Y}$ & $\mathrm{N}$ & $\mathrm{N}$ & $\mathrm{N}$ & $\mathrm{N}$ & \\
\hline Amesquita [55] & 52 & M & 23 & 99 & $\mathrm{Y}$ & $\mathrm{N}$ & Y & $\mathrm{N}$ & $\mathrm{N}$ & $\mathrm{N}$ & $\mathrm{N}$ & Cough \\
\hline Boari [56] & 67 & M & 18 & 97 & $\mathrm{~N}$ & $\mathrm{~N}$ & $\mathrm{Y}$ & $\mathrm{N}$ & $\mathrm{N}$ & $\mathrm{N}$ & $\mathrm{N}$ & \\
\hline Migneault [57] & 63 & $\mathrm{~F}$ & 20 & 97 & $\mathrm{~N}$ & $\mathrm{~N}$ & Y & $\mathrm{N}$ & $\mathrm{N}$ & $\mathrm{N}$ & $\mathrm{N}$ & \\
\hline Heavrin [23] & 29 & $\mathrm{~F}$ & 16 & 100 & $\mathrm{Y}$ & $\mathrm{N}$ & Y & $\mathrm{N}$ & $\mathrm{N}$ & $\mathrm{N}$ & $\mathrm{N}$ & Pleuritic pain \\
\hline Sethuraman [58] & 14 & M & 20 & 99 & $\mathrm{~N}$ & $\mathrm{~N}$ & Y & $\mathrm{N}$ & $\mathrm{N}$ & $\mathrm{N}$ & $\mathrm{N}$ & \\
\hline Sethuraman [58] & 21 & $M$ & 18 & 100 & $\mathrm{Y}$ & $\mathrm{N}$ & $\mathrm{Y}$ & $\mathrm{N}$ & $\mathrm{N}$ & $\mathrm{N}$ & $\mathrm{N}$ & Cough, pleuritic pain \\
\hline Noble [59] & 51 & $M$ & 32 & 100 & $\mathrm{~N}$ & $\mathrm{~N}$ & $\mathrm{~N}$ & $Y$ & $\mathrm{~N}$ & $\mathrm{~N}$ & $\mathrm{~N}$ & \\
\hline Falterman [60] & 62 & M & 18 & 99 & $\mathrm{Y}$ & $\mathrm{N}$ & $\mathrm{N}$ & $\mathrm{Y}$ & $\mathrm{N}$ & Y & $\mathrm{N}$ & Dyspneoa \\
\hline Lee [61] & 63 & $\mathrm{~F}$ & 16 & 98 & $\mathrm{Y}$ & $\mathrm{N}$ & $\mathrm{N}$ & $\mathrm{Y}$ & $\mathrm{N}$ & $\mathrm{N}$ & $\mathrm{N}$ & Chest pain \\
\hline Pillarisetti [62] & 55 & $M$ & 16 & 97 & $\mathrm{Y}$ & $\mathrm{N}$ & $\mathrm{N}$ & $\mathrm{N}$ & $\mathrm{Y}$ & $\mathrm{N}$ & $\mathrm{N}$ & Dyspneoa \\
\hline Alreshq [63] & 92 & M & 16 & 95 & $\mathrm{~N}$ & $\mathrm{~N}$ & $\mathrm{~N}$ & $\mathrm{~N}$ & $\mathrm{~N}$ & $\mathrm{Y}$ & $\mathrm{N}$ & Near-syncope \\
\hline Lu [64] & 21 & M & 18 & 95 & $\mathrm{~N}$ & $\mathrm{~N}$ & $\mathrm{~N}$ & $\mathrm{~N}$ & $\mathrm{~N}$ & $\mathrm{~N}$ & $\mathrm{Y}$ & \\
\hline Meyer [65] & 50 & M & NA & 100 & $\mathrm{~N}$ & $\mathrm{~N}$ & $\mathrm{~N}$ & $\mathrm{~N}$ & $\mathrm{~N}$ & $\mathrm{~N}$ & $\mathrm{Y}$ & \\
\hline Bhatty [66] & 60 & M & 14 & 95 & $\mathrm{Y}$ & $\mathrm{N}$ & $\mathrm{N}$ & NA & $\mathrm{N}$ & $\mathrm{N}$ & $\mathrm{N}$ & Aortic dissection \\
\hline Al-Zuabi [67] & 70 & $\mathrm{~F}$ & NA & 100 & NA & $\mathrm{N}$ & NA & NA & NA & $\mathrm{N}$ & $\mathrm{N}$ & Aortic dissection \\
\hline Tomaszuk-Kazberuk [68] & 69 & M & 18 & 96 & $\mathrm{Y}$ & $\mathrm{N}$ & $\mathrm{N}$ & Y & $\mathrm{N}$ & $\mathrm{N}$ & $\mathrm{N}$ & Aortic dissection \\
\hline
\end{tabular}

Key: F: Female; M: Male; RR: Respiratory Rate; $\mathrm{SaO}_{2}$ : Oxygen saturation on room air; PE: Pulmonary Embolism; N: No; Y: Yes; NA: Not available; Abdo: abdominal

\section{Atypical PE-related symptomatology associated with $\mathrm{SaO}_{2}$ of $95 \%$ or more}

(i) This was exemplified by an 18 year old woman who presented with sudden worsening of dyspnoea on minimal exertion. Her pulse rate was 52-56/minute, RR 18 breaths/ minute, $\mathrm{SaO}_{2}$ amounting to ninety nine percent whilst breathing room air. Computed tomography pulmonary angiogram showed a large embolus in the main pulmonary trunk extending into both the right and left pulmonary arteries [51].

(ii) In another report, an 18 year old woman presented with chest pain and abdominal pain. Her RR was 28 breaths/ min, and her $\mathrm{SaO}_{2}$ was 99\% (breathing room air). CTPA showed bilateral basilar segmental and sub segmental filling defects consistent with PE [52].

Atypical PE-related symptomatology associated with $\mathrm{SaO}_{2}$ of $95 \%$ or more.

\section{(a) PE-related hiccup with $\mathrm{SaO}_{2}$ of $95 \%$ or more}

This was exemplified by an 81 year old man who presented with hiccup, and also without concurrent dyspnoea or abdominal pain. His RR was 20 breaths/minute, $\mathrm{SaO}_{2} 98 \%$ (breathing room air). CTPA showed an embolus in the anterior and lateral segments of the left lower lobe pulmonary artery [53].

(b) PE-related abdominal pain with $\mathrm{SaO}_{2}$ of $95 \%$ or more

(i) This was a 42 year old man who complained of right flank and lower abdominal pain. $\mathrm{SaO}_{2}$ was $97 \%$ (breathing room air). CTPA revealed an embolus in the lower branch of right lower lobar pulmonary artery [54].

(ii) In another report a 48 year old man presented with right upper quadrant abdominal pain. His RR was 16 breaths/ minute, $\mathrm{SaO}_{2} 99 \%$ breathing room air. CTPA showed a large central embolus in the right main pulmonary artery [18].

(iii) This was a 44 year old man with right upper quadrant abdominal pain and no dyspnoea. $\mathrm{SaO}_{2}$ amounted to $98 \%$ breathing room air. CTPA showed an embolism involving the right posterior segmental arteries [26].

(iv) A 53 year old man complained of lower right back pain radiating to the right upper quadrant of the abdomen. He denied chest pain or dyspnoea. His RR was 22 breaths/minute, $\mathrm{SaO}_{2}$ 96\% (breathing room air). CTPA showed an embolus in the segmental branch of the right lower lobe [27].

(v) A 52 year old man complained of right flank pain in association with right upper quadrant pain. He also complained of dry cough. His RR was 23 breaths/minute, $\mathrm{SaO}_{2}$ $99 \%$ breathing room air. CTPA showed pulmonary emboli in the segmental branches of the right lower lobe pulmonary artery [55].

(vi) A 67 year old man complained of left flank pain radiating to the left upper quadrant of the abdomen. His RR was 18 breaths/minute, $\mathrm{SaO}_{2}$ 97\% (breathing room air). CTPA showed occlusion of the lower branch of the right pulmonary artery [56].

(vii) A 63 year old woman complained of right upper 
quadrant abdominal pain worsened by breathing. She denied chest pain or dyspnoea. Her RR was 20 breaths/min, $\mathrm{SaO}_{2}$ 97\% (breathing room air). PE was initially thought to be unlikely, but she subsequently deteriorated. A subsequent CTPA showed bilateral extensive pulmonary embolism [57].

(viii) A 29 year old woman presented with a history of abdominal pain which subsequently proved to be attributable to ovarian vein thrombosis. Her RR was 16 breaths/min. $\mathrm{SaO}_{2}$ was $100 \%$ on room air. Her CT scan was "diagnostic of pulmonary embolism" [23].

(ix) A 14 year old boy complained of left sided abdominal pain, His RR was twenty breaths/min, $\mathrm{SaO}_{2} 100 \%$ breathing room air. CTPA showed bilateral lower lobe PE [58].

(x) A 21 year old man complained of left upper quadrant abdominal pain. His RR was 18 breaths/min. $\mathrm{SaO}_{2}$ was $100 \%$ (breathing room air). CTPA revealed a "large left and small right PE and left lower lobe infarct" [58].

(c) PE-related ST segment elevation in association with $\mathrm{SaO}_{2} 95 \%$ or more.

(i) The work up of a 51 year old man with a history of recent transient hypotension included an ECG which showed ST segment elevation in leads V1-V3. His RR was 32 breaths/min, $\mathrm{SaO}_{2} 100 \%$ on room air. CTPA revealed a large saddle embolus extending from the pulmonary trunk into all branches of the right pulmonary artery, "resulting in markedly decreased blood flow to the entire right lung" [59].

(ii) A 62 year old man presented with a history of syncope and acute onset dyspnoea. His RR was 18 breaths/ min, and his $\mathrm{SaO}_{2}$ was $99 \%$ on room air. His ECG showed ST segment elevation in leads V1 to V4. He subsequently became haemodynamically unstable and died. Autopsy revealed that he did not have AMI, but that he had died of pulmonary embolism [60].

(iii) A 63 year old woman presented with a history of central chest pain cough. Her RR was $16 / \mathrm{min}$ and $\mathrm{SaO}_{2}$ was $98 \%$ on room air. Her ECG showed progressive concave ST segmentation in the anterior leads, and her Wells score indicated low probability of PE. A subsequent CTPA showed multiple right-sided pulmonary emboli [61].

(d) PE-related "giant" $\mathrm{T}$ wave inversion associated with $\mathrm{SaO}_{2} 95 \%$ or more.

A 55 year old man complained of mild aching chest discomfort and exertional dyspnoea for a week. His RR was 16 breaths/min, $\mathrm{SaO}_{2}$ was $97 \%$. His ECG showed giant T wave inversion simulating high-grade stenosis of the proximal left anterior descending artery. CTPA showed large bilateral emboli that were partially occlusive of both main pulmonary arteries [62].

(e) PE-related near-syncope with $\mathrm{SaO}_{2}$ of $95 \%$ or more
A 92 year old man presented with a history of lightheadedness followed by a fall. His ECG showed sinus bradycardia (heart rate 48 beats $/ \mathrm{min}$ ) and first degree atrioventricular block. His respiratory rate was 16 breaths/ min, and his $\mathrm{SaO}_{2}$ was 95\%. A ventilation/perfusion scan showed evidence of a high probability PE with involvement of $>50 \%$ of the pulmonary vasculature [63].

(f) PE-related seizures and $\mathrm{SaO}_{2}$ of $95 \%$ or more.

(i) A 21 year old man gave a history of two recent episodes of convulsions and recent onset dyspnoea. His RR was 18 breaths/min and his $\mathrm{SaO}_{2}$ was $95 \%$ on room air. Transthoracic echocardiogram showed marked dilatation of the right ventricle and right atrium, moderate -to-sever tricuspid regurgitation, and elevation of pulmonary artery systolic pressure to $82 \mathrm{~mm} \mathrm{Hg}$. CTPA showed "filling defects over bilateral pulmonary arteries" [64].

(ii) A 50 year old man presented with a history of seizures, but no history of dyspnoea or chest pain. $\mathrm{SaO}_{2}$ was initially $100 \%$ except for a brief spell of tachycardia followed by bradycardia and a brief spell of $\mathrm{SaO}_{2}$ in the $80 \mathrm{~s}$ range. Transthoracic echocardiography showed an increase in pulmonary artery pressure, thereby raising the index of suspicion for PE. Ventilation/perfusion scan showed multiple areas of mismatch. He subsequently experienced cardiopulmonary arrest and died. Autopsy showed a saddle pulmonary embolism and massive bilateral emboli [65].

(g) Coexistence of PE and dissecting aortic aneurysm in the presence of $\mathrm{SaO}_{2}$ of $95 \%$ or more.

Three patients, aged 60,69 , and 70, respectively, had PE coexisting with dissecting thoracic aortic aneurysm. Their corresponding $\mathrm{SaO}_{2}$ levels (on room air) were 95\%, 100\% and 96\%, respectively. Data on these three patients [66-68], and six others with the association of PE and dissecting thoracic aortic aneurysm are depicted in table 3.

\section{Atypical electrocardiographic stigmata of pulmonary embolism}

Typical ECG stigmata of PE include sinus tachycardia, S1Q3T3 configuration, T wave inversion in leads V1-V4, RBBB, and supraventricular tachyarrhythmias [69]. A Qr pattern in V1 signifies poor prognosis [70]. Atypical features include sinus bradycardia [51], ST segment elevation simulating STEMI [13], "Giant” T wave inversion in leads V1-V4 [62], LBBB [71], Brugada pattern [72,73], CHB [74], ventricular fibrillation [75], and pulseless electrical activity [75], the latter sometimes associated with good outcome if its underlying cause(PE) is promptly identified and appropriately managed [76].

Atrial fibrillation deserves special mention when PE originates from a right atrial thrombus [77]. 
Table 3: Coexisting aortic dissection and pulmonary embolism.

\begin{tabular}{|c|c|c|c|c|c|c|c|c|}
\hline First author and reference & Age & Sex & $\mathbf{R R}$ & $\mathrm{SaO}_{2} \%$ & Dyspnoea & Chest pain & Backache & Comments \\
\hline M'ludoran [84] & 70 & M & NA & 78 & $\mathrm{Y}$ & $\mathrm{Y}$ & $\mathrm{N}$ & D-dimer $18.6 \mathrm{mcg} / \mathrm{ml}$ \\
\hline Tomaszuk-Kazberuk [68] & 69 & M & 18 & 96 & $\mathrm{~N}$ & $\mathrm{Y}$ & $\mathrm{Y}$ & DVT common femoral vein \\
\hline Leu [82] & 57 & $\mathrm{~F}$ & NA & NA & $\mathrm{Y}$ & $\mathrm{N}$ & $\mathrm{N}$ & \\
\hline Ramponi [85] & 75 & M & NA & NA & Y & $\mathrm{Y}$ & Y & Saddle PE \\
\hline Chai [86] & 46 & $\mathrm{~F}$ & NA & NA & $\mathrm{N}$ & Y & $\mathrm{N}$ & DVT popliteal vein \\
\hline Bhatty [66] & 60 & M & 14 & 95 & Y & $\mathrm{Y}$ & $\mathrm{N}$ & DVT right leg \\
\hline Cruz [87] & 71 & $\mathrm{~F}$ & NA & NA & Y & $\mathrm{Y}$ & $\mathrm{N}$ & \\
\hline Al-Zuabi [67] & 70 & $\mathrm{~F}$ & NA & 100 & NA & NA & NA & Dementia \\
\hline Akgul [83] & 61 & M & NA & NA & $\mathrm{Y}$ & NA & Y & DVT right popliteal femoral and iliac veins \\
\hline
\end{tabular}

Key: F: Female; M: Male; RR: Respiratory Rate; $\mathrm{SaO}_{2}$ : Oxygen saturation on room air; N: No; Y: Yes; NA: Not available

Coexistence of pulmonary embolism and thoracic aortic dissection (Table 3)

Thoracic aortic dissection (TAD) can fortuitously coexist with PE. Misdiagnosis may be attributable to the fact that both disorders may be characterized by chest pain and dyspnea [78], pleuritic pain and haemoptysis [79], and elevation in serum D-dimer levels [80]. Furthermore, a Taiwanese nationwide cohort study showed that, after adjusting for age, sex, and duration of hospitalisation, patients with aortic aneurysms(AA) were associated with a 1.88-fold higher risk of DVT (95\% Confidence Interval 1.52 to 2.33 ) and a 1.90 -fold higher risk of PE (95\% CI 1.58 to 2.25) compared with the nonAA cohort. The authors hypothesized that this might, in part, be attributable to compression of the superior vena cava leading to venous stasis and heightened risk of thrombus formation [81]. Among nine anecdotal reports of the association of TAD and PE [66-68, 82-87] there were four instances of coexisting DVT $[66,68,83,87]$.

\section{Neurological manifestations of PE other than stroke}

The occurrence of seizures is an occasional manifestation of PE $[64,65]$. Syncope without concurrent signs and symptoms of venous thromboembolism is another atypical manifestation of PE. In one study, among 97 patients of mean age 77 with syncope as a manifestation of PE, there were 24 who had no manifestations of PE such as tachypnoea, tachycardia, hypotension or clinical signs or symptoms of DVT [88].

Delirium was attributable to PE in 5 patients aged $72-85$, three of whom also had symptoms including chest pain and left calf swelling, acute dyspnoea, and sudden worsening dyspnoea, respectively. In the other two patients those symptoms were absent, and unexplained D-dimer increase was the only manifestation of $\mathrm{PE}$. $\mathrm{PaO}_{2}$ amounted to $<80$ $\mathrm{mmHg}$ in four patients, but was documented as $83 \mathrm{mmHg}$ in the fifth patient [89].

\section{Pulmonary embolism-related PDE (Table 4)}

In one study silent PE (identified by ventilation/perfusion imaging) had a documented prevalence of $37 \%$ among 151 patients with PDE [90]. However, in another study among 113 consecutive patients (mean age 62) with suspected cardiogenic embolicstrokeand patent foramen ovale(PFO),CTPAidentified only 4 patients with PE [91]. An analysis of 12 anecdotal reports of PE-related PDE [92-105] reveals three patterns of clinical presentation (Table 4), namely, simultaneous occurrence of typical PE symptoms(or hypoxaemia) and symptoms of PDE, occurrence of PE symptoms followed by occurrence of stroke a day or so later, and occurrence of stroke without any documentation of breathlessness. In the latter category were four patients [102-105] in whom PDE-related stroke occurred in a PE patient who had reported neither breathlessness, chest pain or cough. Nevertheless, subsequent transthoracic echocardiography(TTE) revealed either right heart dilatation and elevation in pulmonary artery systolic pressure[103], or intracardiac thrombus[102, 104,105], thereby raising the index of suspicion for PE. The utility of TTE in identifying PE in patients with PDE [102-105] has its counterpart in the utility of TTE for differentiating PE from suspected AMI [106]. In the latter case report a 32 year old man presented with anterior chest pain and dyspnoea, and he had ST segment elevation in V3-V6. TTE revealed right ventricular dilatation and dysfunction, and flattening of the interventricular septum signifying possible PE. The latter diagnosis was validated by CTPA [106]. TTE can also raise the index of suspicion for PDE in a patient with an acute exacerbation of asthma [107]. In the latter report a 69 year old woman with known asthma experienced an exacerbation of her symptoms which was accompanied by the occurrence of left upper limb pain. TTE revealed a tricuspid regurgitation peak gradient of $47 \mathrm{~mm} \mathrm{Hg}$ which was indicative of pulmonary hypertension. Enhanced computed tomography revealed saddle PE. The left brachial artery was not delineated. Subsequent transoesophageal echocardiography revealed a PFO with right-to-left shunt during the Vasalva manouvre [107]. TTE can even identify the coexistence of PE and TAD, as in a 71 year old woman who presented with dyspnoea and angina. On examination she had DVT in one leg, and also had aortic regurgitation. TTE showed a thrombus in the right pulmonary artery, and stigmata of TAD comprising a dilated aortic root, an intimal flap with image suggestive of a double lumen, and moderate aortic regurgitation [87]. Even in the atypical presentation of PE with seizures TTE can raise the index of suspicion for PE by documenting stigmata consistent with PE $[64,65]$.

\section{Acute venous thromboembolism of atypical location}

In one autopsy study the point of origin of PE was 
Table 4: Pulmonary embolism-related paradoxical embolism

\begin{tabular}{|c|c|c|c|c|c|c|c|}
\hline First author and reference & Age & Sex & $\mathbf{R R}$ & $\mathrm{SaO}_{2} \%$ & $\begin{array}{l}\text { Typical PE symptoms or } \\
\text { hypoxia }\end{array}$ & $\begin{array}{l}\text { Simultaneous paradoxical } \\
\text { embolism symptoms }\end{array}$ & Comments \\
\hline Abusnina [92] & 65 & $\mathrm{~F}$ & 20 & 95 & $\mathrm{Y}$ & Y & $\begin{array}{l}\text { Right axillary artery embolism, DVT involving } \\
\text { left femoral and left popliteal veins }\end{array}$ \\
\hline Belvis [93] & 36 & $\mathrm{~F}$ & NA & NA & $\mathrm{Y}$ & $\mathrm{Y}$ & Simultaneous dyspnoea and right hemiparesis \\
\hline Bazan [94] & 66 & M & NA & NA & Y & $\mathrm{Y}$ & $\begin{array}{c}\text { Simultaneous central cyanosis and bilateral } \\
\text { ischaemic stroke }\end{array}$ \\
\hline Liu [95] & 57 & M & NA & NA & $\mathrm{Y}$ & $\mathrm{Y}$ & $\begin{array}{c}\text { Simultaneous dyspnoea and right cerebellar } \\
\text { infarct }\end{array}$ \\
\hline Vyas [96] & 66 & $\mathrm{~F}$ & 22 & 96 & $\mathrm{Y}$ & $\mathrm{Y}$ & Simultaneous dyspnoea and stroke \\
\hline Gansera [97] & 32 & $\mathrm{~F}$ & NA & NA & $\mathrm{Y}$ & $\mathrm{Y}$ & Simultaneous dyspnoea and hemiplegia \\
\hline Lapostolle [98] & 53 & $\mathrm{~F}$ & NA & NA & Y & Y & Simultaneous hypoxaemia and hemiplegia \\
\hline Lapostolle [98] & 67 & $\mathrm{~F}$ & NA & 85 & $\mathrm{Y}$ & $\mathrm{Y}$ & Simultaneous hypoxaemia and hemiparesis \\
\hline Lapostolle [98] & 51 & $\mathrm{~F}$ & NA & 88 & $\mathrm{Y}$ & Y & Simultaneous dyspnoea and hemiplegia \\
\hline Lapostolle [98] & 56 & M & NA & NA & $\mathrm{Y}$ & $\mathrm{Y}$ & $\begin{array}{l}\text { Oxygen saturation } 95 \% \text {, breathing 3L oxygen/ } \\
\text { min, hemiplegia }\end{array}$ \\
\hline Facciorusso [99] & 73 & $\mathrm{~F}$ & NA & & $\mathrm{Y}$ & $\mathrm{N}$ & Dyspnoea followed by stroke 4 weeks later \\
\hline Almaghraby [100] & 61 & M & 24 & NA & $\mathrm{Y}$ & $\mathrm{N}$ & $\begin{array}{c}\text { Dyspnoea followed by stroke } 2 \text { days later. Deep } \\
\text { vein thrombosis in both lower limbs }\end{array}$ \\
\hline Mirijello [101] & 58 & M & NA & 94 & $\mathrm{Y}$ & $\mathrm{N}$ & $\begin{array}{l}\text { Pleuritic pain followed by stroke the following } \\
\text { day }\end{array}$ \\
\hline First author and reference & Age & Sex & $\mathrm{RR}$ & $\mathrm{SaO}_{2} \%$ & $\begin{array}{l}\text { Typical PE symptoms or } \\
\text { hypoxia }\end{array}$ & $\begin{array}{l}\text { Simultaneous paradoxical } \\
\text { embolism symptoms }\end{array}$ & Comments \\
\hline Kumar [102] & 32 & M & NA & NA & $\mathrm{N}$ & $\mathrm{N}$ & $\begin{array}{c}\text { Stroke and echocardiogram showing thrombus } \\
\text { in foramen ovale, thrombus in main pulmonary } \\
\text { artery. DVT right common iliac vein }\end{array}$ \\
\hline Cameron [103] & 53 & M & 31 & NA & $\mathrm{N}$ & $\mathrm{N}$ & $\begin{array}{l}\text { Hemiparesis and echocardiogram showing } \\
\text { right ventricular dilatation and pulmonary } \\
\text { hypertension. CTPA showed PE }\end{array}$ \\
\hline Dada [104] & 55 & M & NA & NA & $\mathrm{N}$ & $\mathrm{N}$ & $\begin{array}{l}\text { Hemiparesis and echocardiogram showing } \\
\text { patent foramen ovale, right atrial embolus and } \\
\text { pulmonary embolus }\end{array}$ \\
\hline Miriyala [105] & 72 & M & NA & NA & $\mathrm{N}$ & $\mathrm{N}$ & $\begin{array}{l}\text { Hemiparesis and echocardiogram showing } \\
\text { thrombus in right atrium and foramen ovale and } \\
\text { pulmonary artery. Bilateral lower limb DVT }\end{array}$ \\
\hline
\end{tabular}

Key: F: Female; M: Male; RR: Respiratory Rate; $\mathrm{SaO}_{2}$ : Oxygen saturation on room air; N: No; Y: Yes; NA: Not available

identified in 102 out of two hundred cases of proven PE. In $36.9 \%$ of cases point of origin included periureteric plexus, superior vena cava, and right atrium [108]. A systematic review of twenty nine publications revealed that DVT of the upper extremity constituted $4 \%$ to $10 \%$ of all DVT during the period January 1980 to May 2016 [109]. Internal jugular vein thrombosis, exemplified by Lemierre's syndrome is another risk factor for PE [110].

Exceptionally, jugular venous thrombosis can be complicated by the occurrence of paradoxical embolism, as was the case in a 23 year old woman who presented with chest pain and breathlessness, in the context of previous documentation of right internal jugular vein thrombosis. In addition to CTPA-validated PE she had angiographic evidence of emboli to the arm and leg [111].

\section{Pulmonary thromboembolism with normal serum D-dimer levels}

Although an elevated D-dimer level is a useful confirmatory test for PE, a prospective study of 1,632 subjects in the age range 20-100 identified 8 patients aged 28-71 with CTPAvalidated PE in whom D-dimer levels did not exceed 500 $\mathrm{mcg} / \mathrm{L}[112]$.

An age-adjusted D-dimer evaluation (age x $10 \mathrm{mcg} / \mathrm{L}$ with a lower limit of $500 \mathrm{mcg} / \mathrm{L}$ ) does not necessarily mitigate the risk of misdiagnosis of PE. A missed diagnosis of PE was documented in a 75 year old man with a normal age-adjusted D-dimer level. He had presented with recent-onset progressive dyspnoea, wheezing, and cough. The oxygen saturation whilst breathing room air was 93\%. Atypically, his Wells score was zero, and his age-adjusted D-dimer was $600 \mathrm{mcg} / \mathrm{L}$ (normal level for age-adjusted D-dimer). In spite of atypical clinical presentation (ie Wells score of zero) and atypically normal age-adjusted D-dimer, CTPA showed several segmental emboli in both upper and lower parts of the right lung [113].

\section{Summary of the prevalence of some of the atypical manifestations}

Evaluation of anecdotal reports of atypical manifestations of PE is fraught with limitations attributable to publication bias. Within the constraints imposed by those limitations the following generalisations are possible:-

(i) Presentation of PE with STEMI-like ST segment elevation is a rare entity, generating only 34 case reports in a recent systematic review. Nevertheless, it emerged that PErelated ST segment elevation occurs predominantly in the anteroseptal distribution [13].

(ii) Presentation with gradual onset dyspnoea is prevalent in approximately $3 \%$ of patients with PE $[30,114]$. 
(iii) Orthopnoea is rare, occurring in approximately in $1 \%$ of PE patients $[30,114]$

(iv) Oxygen saturation of $<95 \%$ (while breathing room air) generates an Odds Ratio of 3.3 in favour of the diagnosis of PE among patients with suspected PE [3].

(v) Syncope is prevalent in approximately $22 \%-26 \%$ of PE patients [30],[114].

(vi) PE-related paradoxical embolism is rare, and stroke is its commonest manifestation. Among patients with embolic stroke associated with patent foramen ovale, the prevalence of PE may only be $3.5 \%$ [9].

(vii) Deep vein thrombosis of atypical location is a rare risk factor for PE. Upper limb DVT is a specific example, prevalent in $4 \%-10 \%$ of all patients with DVT [109]

(viii) Approximately $0.5 \%$ of PE patients have D-dimer levels amounting to $<500 \mathrm{mcg} / \mathrm{L}$ (ie the normal reference range) [112].

\section{Conclusion}

Atypical manifestations of PE may occur in patients who already have at least one other symptom or sign which has been enumerated in a CDR or in PERC. If an atypical symptom dominates the clinical picture the risk is that a diagnosis other than PE might seem more likely. The index of suspicion for $\mathrm{PE}$ is even more likely to be diminished if atypical signs and symptoms are the sole presenting features of $\mathrm{PE}$, thereby making an alternative diagnosis even more likely than PE. The latter scenario is exemplified by initial sole presentation of PE as abdominal pain, hoarseness, hiccups, seizures, syncope, or paradoxical embolism, respectively, without concurrent dyspnoea, and also without concurrent chest pain. Attention to atypical symptoms and signs of PE, and awareness of the entire range of manifestations of PE can improve the level of pulmonary embolism diagnosis.

\section{References}

1. Wells PS, Ginsberg JS, Anderson DR, Kearon C, Gent M, et al. Use of a clinical model for safe management of patients with suspected pulmonary embolism. Ann Intern Med. 1998; 129: 997-1005.

PubMed: https://www.ncbi.nlm.nih.gov/pubmed/9867786

2. Wells PS, Anderson DR, Rodger M, Ginsberg JS, Kearon C, et al. Derivation of a simple clinical model to categorize patients probability of pulmonary embolism: Increasing the model's utility with the simpliRED D-dimer. Thromb Haemost. 2000; 83: 416-420.

PubMed: https://www.ncbi.nlm.nih.gov/pubmed/10744147

3. Kline JA, Mitchell AM, Kabrhel C, Richman PB, Courtney DM, Clinical criteria to prevent unnecessary diagnostic testing in emergency department patients with suspected pulmonary embolism. J Thromb Haemost 2004; 2: 1247-1255.

PubMed: https://www.ncbi.nlm.nih.gov/pubmed/15304025

4. Kline JA, Courtney DM, Kabrhel C, Moore CL, Smithline HA, et al. Prospective multicentre evaluation of the pulmonary embolism rule-out criteria. J Thromb Haemost. 2008; 6: 772-780.

PubMed: https://www.ncbi.nlm.nih.gov/pubmed/18318689
5. Pauker S, Kassirer JP. The threshold approach to clinical decision making. N Engl J Med. 1980; 302: 1109-1117.

PubMed: https://www.ncbi.nlm.nih.gov/pubmed/7366635

6. Turedi S, Erdem E, Karaca Y, Tatli O, Sahin A, et al. The high risk of contrast-induced nephropathy in patients with suspected pulmonary embolism despite three different prophylaxis: A randomized controlled trial. Acad Emerg Med. 2016; 23: 1136-1145.

PubMed: https://www.ncbi.nlm.nih.gov/pubmed/27411777

7. Kabrhel C, Camargo CA, Goldhaber SZ. Clinical gestalt and the diagnosis of pulmonary embolism: does experience matter? CHEST 2005; 127: 1627-1630.

PubMed: https://www.ncbi.nlm.nih.gov/pubmed/15888838

8. Egermayer P, Town GI, Turner JG, Heaton DC, Mee A, et al. Usefulness of D-dimer, blood gas, and respiratory rate measurements for excluding pulmonary embolism. Thorax. 1998; 53: 830-834. PubMed: https://www.ncbi.nlm.nih.gov/pmc/articles/PMC1745091/

9. Garcia-Fuster MJ, Fabia MJ, Furio E, Pichler G, Redon MJ, et al Should we look for silent pulmonary embolism in patients with deep venous thrombosis? BMC Cardiovascular Disorders. 2014; 14: 178. PubMed: https://www.ncbi.nlm.nih.gov/pubmed/25487168

10. Cha SI, Shin KM, Lee JW, Lee J, Lee SY, et al. Clinical characteristics of patients with peripheral pulmonary embolism. Respiration. 2010; 80: 500-508.

PubMed: https://www.ncbi.nlm.nih.gov/pubmed/20110642

11. Riedel M. Acute pulmonary embolism. 1: pathophysiology, clinical presentation, and diagnosis. Heart. 2001; 85: 229-240.

PubMed: https://www.ncbi.nlm.nih.gov/pmc/articles/PMC1729607/

12. Kukla P, Diugopolski R, Krupa E, Furtak R, Mirek-Bryniarska E, et al. How often pulmonary embolism mimics acute coronary syndrome? Kardiologia Polska. 2011; 69: 235-240.

PubMed: https://www.ncbi.nlm.nih.gov/pubmed/21432791

13. Villablanca PA, Vlismas PP, Aleksandrovich T, Omondi A, Gupta T, et al. Case report and systematic review of pulmonary embolism mimicking ST-elevation myocardial infarction. Vascular. 2019; 27: 90-97.

PubMed: https://www.ncbi.nlm.nih.gov/pubmed/30056785

14. Boukantar M, Lim P, Mitchell-Heggs L. Right ventricular thrombus and pulmonary embolism in a patient with anterior myocardial infarction. Eur Heart J. 2010; 31: 2870.

PubMed: https://www.ncbi.nlm.nih.gov/pubmed/20693171

15. Alkhalil M, Cahill TJ, Boardaman H, Choudhury RP. Concomitant pulmonary embolism and myocardial infarction due to paradoxical embolism across a patent foramen ovale. Eur Heart J Case Reports. 2017; 1: 1-4.

PubMed: https://www.ncbi.nlm.nih.gov/pubmed/31020069

16. Al-Mane N, Al-Mane F, Abdalla Z, McDonnell J. Acute surgical abdomen: An unusual presentation of pulmonary embolus. J Investig Med High Impact Case Rep. 2014; 2: 2324709614542339.

PubMed: https://www.ncbi.nlm.nih.gov/pubmed/26425615

17. Pilipp J, Norbert W, Thomas G. Young woman with dyspnoea and upper abdominal pain. Eur J Intern Med. 2019; 59: e1-e2. PubMed: https://www.ncbi.nlm.nih.gov/pubmed/29754937

18. Gantner J, Keffeler J, Derr C. Pulmonary embolism: An abdominal pain masquerader. J Emerg Trauma Shock. 2013; 6: 280-282. PubMed: https://www.ncbi.nlm.nih.gov/pubmed/24339662

19. Fallahi MJ, Masoompour S, Mirzaee M. Pulmonary embolism with abdominal pain and ST elevation: A case report. Iran J Med Sci. 2014; 39: 395-398.

PubMed: https://www.ncbi.nlm.nih.gov/pmc/articles/PMC4100053/

20. Hodkinson EC, Noad RL, menown IBA. Massive pulmonary embolus presenting with abdominal pain. Ulster Med J. 2012; 81: 98. PubMed: https://www.ncbi.nlm.nih.gov/pmc/articles/PMC3605544/ 
21. Lusiani L, Perrone A, Pesavento R, Conte G. Prevalence, clinical features, and acute course of atypical myocardial infarction. Angiology. 1994; 45: 49-55.

PubMed: https://www.ncbi.nlm.nih.gov/pubmed/8285384

22. Israel HL, Goldstein F. The varied clinical manifestations of pulmonary embolism. Ann Intern Med. 1957; 47: 202-226.

PubMed: https://www.ncbi.nlm.nih.gov/pubmed/13459102

23. Heavrin BS, Wrenn K. Ovarian vein thrombosis: a rare cause of abdominal pain outside the peripartum period. J Emerg Med. 2008; 34: 67-69.

PubMed: https://www.ncbi.nlm.nih.gov/pubmed/18194726

24. Vavuranakis M, Lazaros G, Patialiakas A, maragiannis D, Papaioannou, et al. A young woman with syncope, dyspnoea and abdominal pain. Hellenic J Cardiol. 2009; 50: 218-220.

PubMed: https://www.ncbi.nlm.nih.gov/pubmed/19465364

25. Turedi S, Gunduz A, Eroglu O. Paradoxical embolism involving 4 organ systems(pulmonary, renal, splenic, and hepatic artery). Am J Emerg Med. 2007; 25: 737.e1-737.e3.

PubMed: https://www.ncbi.nlm.nih.gov/pubmed/17606114

26. Hosein AS, Mahabir V, Konduru SKP, Giddings SL. Pulmonary embolism: An often forgotten differential diagnosis for abdominal pain. QJ Med. 2019; 112: 689-690.

PubMed: https://www.ncbi.nlm.nih.gov/pubmed/31173142

27. Rehman H, John E, Parikh P. Pulmonary embolism presenting as abdominal pain: An atypical presentation of a common diagnosis. Case Reports in Emergency Medicine. 2016; 2016: 7832895

PubMed: https://www.ncbi.nlm.nih.gov/pmc/articles/PMC5013217/

28. Cohen D, Lyon M, Johnson RP. Frequency of abdominal pain as the presenting complaint in pulmonary embolism. Ann Emergency Med. 2008; 52: S 137; Poster 315.

29. Stein PD, Beemath A, Matta F, Weg JG, Yusen RO, et al. Clinica characteristics of patients with acute pulmonary embolism: Data from PIOPED II. Am J Med. 2007; 120: 871-879.

PubMed: https://www.ncbi.nlm.nih.gov/pubmed/17904458

30. Miniati M, Monti S, Bottai M. A structured clinical model for predicting the probability of pulmonary embolism. Am J Med. 2003; 114: 173-179. PubMed: https://www.ncbi.nlm.nih.gov/pubmed/12637130

31. Alonso-Martinez JL, Sanchez FJA, Echezarreta U. Delay and misdiagnosis in sub-massive and non-massive acute pulmonary embolism. Eur J Intern Med. 2010; 21: 278-282.

PubMed: https://www.ncbi.nlm.nih.gov/pubmed/20603035

32. Salvetti M, Bazza A, Paini A, Bertacchini F. Platypnoea orthodeoxia with pulmonary embolism. American J Emerg Med. 2013; 31: 760e1760e2.

PubMed: https://www.ncbi.nlm.nih.gov/pubmed/23380102

33. Windebank WJ, Boyd G, Moran F. Pulmonary thromboembolism presenting as asthma. Br Med J. 1973; 1: 90-94.

PubMed: https://www.ncbi.nlm.nih.gov/pmc/articles/PMC1588813/

34. Calvo-Romero JM, Perez-Miranda M, Bureo-Dacal $P$. Wheezing in patients with acute pulmonary embolism with and without previous cardiopulmonary disease. Eur J Emerg Med. 2003; 10: 288-289. PubMed: https://www.ncbi.nlm.nih.gov/pubmed/14676506

35. Zoller B, Pirouzifard M, Memon AA, Sundquist J, Sundquist K, Risk of pulmonary embolism and deep vein thrombosis in patients with asthma: a nationwide case-control study from Sweden. Eur J Respir J 2017; 49: 1601-1614.

PubMed: https://www.ncbi.nlm.nih.gov/pubmed/28202551

36. Aleva FE, Voets LWM, Simons SO, de Mast Q, van der Ven AJAM, et al. Prevalence and localization of pulmonary embolism in unexplained acute exacerbations of COPD. CHEST 2017; 151: 544-554. PubMed: https://www.ncbi.nlm.nih.gov/pubmed/27522956
37. Polverino F, Ricciardi M. Voice box symptoms: A hitherto unknown presentation of pulmonary embolism. Am J Respir Crit Care Med. 2013; 187: 108-110.

PubMed: https://www.ncbi.nlm.nih.gov/pubmed/23281354

38. Webster JR, Saadeh GB, Eggum PR, Suker JR. Wheezing due to pulmonary embolism-Treatment with heparin. N Engl J Med 1966; 274 : 931-933.

PubMed: https://www.ncbi.nlm.nih.gov/pubmed/5908886

39. Hassen G, Singh MM, Yemane-Merriwether S, Ferrante A, Shaw R. Persistent hiccups as a rare presenting symptom of pulmonary embolism. Western J Emerg Med. 2012; 13: 479-484. PubMed: https://www.ncbi.nlm.nih.gov/pubmed/23359617

40. Williams AJ, Yauch DC, Finberg SN, Santiago SM, Fisher HK Pulmonary embolism presenting as adult respiratory distress syndromesupport for a hypothesis. Postgrad Med J. 1982; 58: 290-292. PubMed: https://www.ncbi.nlm.nih.gov/pmc/articles/PMC2426424/

41. Famularo G, Minisola G, Nicotra GC, De Simone C. Massive pulmonary embolism masquerading as pulmonary edema. Amer $\mathrm{J}$ Emerg Med. 2007; 25: 1086.eq-1086.e2.

PubMed: https://www.ncbi.nlm.nih.gov/pubmed/18022516

42. Kazza F, Demla V, Cherian S. Unilateral pulmonary edema, Westermark's sign and Palla's sign in pulmonary embolism. Q J Med 2017; 110: 459-460.

PubMed: https://www.ncbi.nlm.nih.gov/pubmed/28339667

43. Elliott CG, Goldhaber SZ, Visani L, De Rosa M. Chest radiographs in acute pulmonary embolism. Results from the International Cooperative Pulmonary Embolism registry. CHEST 2000; 118: 33-38. PubMed: https://www.ncbi.nlm.nih.gov/pubmed/10893356

44. Sisk PB. Pulmonary thromboembolism: Atypical clinical and roentgen manifestations. CHEST. 1965; 47; 539-548.

PubMed: https://www.ncbi.nlm.nih.gov/pubmed/14285343

45. Mathieson P, Reckless I, Ferrett C. Secondary spontaneous pneumothorax: a rare complication of pulmonary embolism. BMJ Case Rep. 2012;

PubMed: https://www.ncbi.nlm.nih.gov/pubmed/23109413

46. Kadam S, Joshi JM. Pulmonary cavitation and hydropneumothorax associated with pulmonary embolism. Indian $\mathrm{J}$ Chest Dis Allied Sci 2012; 54: 119-121.

PubMed: https://www.ncbi.nlm.nih.gov/pubmed/22973782

47. Vidal E, LeVeen HH, Yarnoz M, Piccone VA. Lung abscess secondary to pulmonary infarction. Ann Thorac Surg. 1971; 11: 557-564.

PubMed: https://www.ncbi.nlm.nih.gov/pubmed/5579103

48. Maldjian PD, Petscavage JM. Intracardiac thrombus and pulmonary embolism with cavitation and pneumomediastinum in a patient with protein S deficiency. J Thorac Imaging 2006; 21: 222-224. PubMed: https://www.ncbi.nlm.nih.gov/pubmed/16915068

49. Jerjez-Sanchez C, Ibarra-Perez C, Ramirez-Rivera A, Padua-Gabriel A, Gonzalez-Carmora VM. Dressler-like syndrome after pulmonary embolism and infarction. CHEST. 1987; 92: 115-117. PubMed: https://www.ncbi.nlm.nih.gov/pubmed/3595222

50. Agarwal R, Singh N, Gupta D. Pleural effusion associated with pulmonary thromboembolism: A systematic review. Indian J Chest Dis Allied Sci. 2009; 51: 159-164.

51. Larsen TR, Ball TC. Chronic pulmonary embolism in a young athletic woman. Proc Baylor Univ Med Cent. 2015; 28: 371-374.

PubMed: https://www.ncbi.nlm.nih.gov/pmc/articles/PMC4462227/

52. Kahanov L, Daly T. Bilateral pulmonary emboli in a collegiate gymnast. J Athl Train. 2009; 44: 666-671.

PubMed: https://www.ncbi.nlm.nih.gov/pmc/articles/PMC2775370/ 
53. Durning SJ, Shaw DJ, Oliva AJ, Morris MJ. Persistent hiccups as the presenting symptom of a pulmonary embolism. Chest Disease Reports 2012; 2 e2.

54. Mansmann EH, Singh A. Pulmonary thromboembolism presenting with abdominal symptoms. Am J Case Rep 2012; 13: 137-139.

PubMed: https://www.ncbi.nlm.nih.gov/pmc/articles/PMC3616185/

55. AmesquitaM, Cocchi MN, Donnino MW. Pulmonaryembolism presenting as flank pain: A case series. J Emerg Med 2012; 42: e97-e100.

PubMed: https://www.ncbi.nlm.nih.gov/pubmed/19327937

56. Boari B, Bergami E, Manfredini R. Abdominal and flank pain as an unusual presentation of pulmonary embolism: A case report. J Am Geriatr Soc. 2005; 53: 1259-1260.

PubMed: https://www.ncbi.nlm.nih.gov/pubmed/16108951

57. Migneault D, Levine Z, de Champlain F. An unusual presentation of a massive pulmonary embolism with misleading investigation results treated with tenecteplase. Case Rep Emerg Med. 2015; 2015: 868519. PubMed: https://www.ncbi.nlm.nih.gov/pmc/articles/PMC4350959/

58. Sethuraman U, Siadat M, Lepak-Hitch CA, Haritos D. Pulmonary embolism presenting as acute abdomen in a child and adult. Am J Emerg Med. 2009; 27: 514.e1-514.e5.

PubMed: https://www.ncbi.nlm.nih.gov/pubmed/19555633

59. Noble J, Singh A. Asymptomatic pulmonary embolus masquerading as anteroseptal myocardial infarction. CJEM. 2011; 13: 62-65. PubMed: https://www.ncbi.nlm.nih.gov/pubmed/21324301

60. Falterman TJ, Martinez JA, Daberkow D, Weiss LD. Pulmonary embolism with ST segment elevation in leads V1 to V4: Case report and review of the literature regarding electrocardiographic changes in acute pulmonary embolism. J Emerg Med. 2001; 21: 255-262. PubMed: https://www.ncbi.nlm.nih.gov/pubmed/11604280

61. Lee DZ, Whittaker M, Al-Mohammad A. An unusual presentation of pulmonary embolism. BMJ Case Reports 2012; 2012: bcr2012006210. PubMed: https://www.ncbi.nlm.nih.gov/pmc/articles/PMC4542928/

62. Pillarisetti J, Gupta K. Giant inverted T waves in the emergency department: case report and review of differential diagnoses. J Electrocardiol. 2010; 43: 40-42.

PubMed: https://www.ncbi.nlm.nih.gov/pubmed/19781716

63. Alreshq R, Hsu G, Torosoff M. Acute pulmonary embolism presenting with symptomatic bradycardia: a case report and review of the literature. Am J case Rep. 2019; 20: 748-752.

PubMed: https://www.ncbi.nlm.nih.gov/pubmed/31130721

64. Lu SH, Wu YS, Huang SC, Lin CS. A rare case of pulmonary embolism and seizure in a young man: Antiphospholipid syndrome. Acta Cardiol Sin. 2016; 32: 247-249.

PubMed: https://www.ncbi.nlm.nih.gov/pmc/articles/PMC4816925/

65. Meyer MA. Seizure as the presenting sign for massive pulmonary embolism: Case report and review of literature. Seizure. 2009; 18; 76-78. PubMed: https://www.ncbi.nlm.nih.gov/pubmed/18656385

66. Bhatty $\mathrm{O}$, Jhand AS, Alkhafaji N, Mooss A. Challenge in clinical decision making: A patient with type $B$ aortic dissection presenting with pulmonary embolism. Am J Resp Crit Care Med. 2017; 195: A4179.

67. Al-Zuabi S, Varkey AP, Abdalmaksoud SF, Alothman HS, Alrashdan I. A rare case of leaking thoracic aortic aneurysm in a patient with massive pulmonary embolism. Egy J Int Med. 2013; 25: 47-50.

68. Tomaszuk-Kazberuk A, Sobkowicz B, Lewczuk A, Prokop JB, Sawicki $R$, et al. Silent pulmonary embolism in a patient with acute myocardia infarction and type B acute aortic dissection-a case report. Adv Med Sci. 2010; 55: 99-102.

PubMed: https://www.ncbi.nlm.nih.gov/pubmed/20371437
69. RaghavKPS, Makkuni P, Figueredo VM. A review of electrocardiography in pulmonary embolism: recognizing pulmonary embolus masquerading as ST-segment elevation myocardial infarction. Rev Cardiovasc Med 2011; 12: 157-163.

PubMed: https://www.ncbi.nlm.nih.gov/pubmed/22145193

70. Casazza F, Pacchetti I, Rulli E, Roncon L, Zonzin P, et al. Prognostic significance of electrocardiogram at presentation in patients with pulmonary embolism of different severity. Thromb Res. 2018; 163: 123-127.

PubMed: https://www.ncbi.nlm.nih.gov/pubmed/29407623

71. Kasmani R, Okoli K, Mohan G, Casey K, Ledrick D. Transient left bundle branch block; An Unusual electrocardiogram in acute pulmonary embolism. Am J Med Sci. 2009; 337: 381-382. PubMed: https://www.ncbi.nlm.nih.gov/pubmed/19322065

72. Wynne J, Littmann L. Brugada electrocardiogram associated with pulmonary embolism. Int J Cardiol. 2013; 162: e32-e33.

PubMed: https://www.ncbi.nlm.nih.gov/pubmed/22664370

73. Lippolis A, Buzzi MP, Romano IJ, Facchini C, gentile F. Syncope in a patient with acute pulmonary embolism and Brugada Type-2 ECG pattern: Brugada phenocopy or Brugada syndrome? J Eelectrocardiol. 2019; 54: 90-92.

PubMed: https://www.ncbi.nlm.nih.gov/pubmed/30965210

74. Zuin M, Rigatelli G. Complete heart block as presenting symptom of massive pulmonary embolism in an elderly patient. J Geriatric Cardiol. 2017; 14; 593-594.

75. Kurkciyan I, Meron G, Sterz F, Janata K, Domanovits $\mathrm{H}$, et al. Pulmonary embolism as a cause of cardiac arrest. Presentation and outcome Arch Intern Med. 2000; 160: 1529-1535.

PubMed: https://www.ncbi.nlm.nih.gov/pubmed/10826469

76. Sharifi M, Berger J, Beeston P, Bay C, Vajo Z, et al. Pulseless electrical activity in pulmonary embolism treated with thrombolysis(from the “PEAPETTI" study). Amer J Emergency Med. 2010; 34: 1963-1967.

77. Bikdeli B, Ziki MDA, Lip GYH. Pulmonary embolism and atrial fibrillation: two sides pf the same coin? A systematic review. Semin Thromb Hemost. 2017; 43; 849-863.

PubMed: https://www.ncbi.nlm.nih.gov/pubmed/28196379

78. Leitman IM, Suzuki K, Wengrofsky AJ, Mebashe E, Poplawski M, et al. Early recognition of acute thoracic aortic dissection and aneurysm. World J Emer Sur. 2013; 8: 47.

PubMed: https://www.ncbi.nlm.nih.gov/pubmed/24499618

79. Warburton MS, Jackson MA, Norton R, Bhabra M. Rare causes of haemoptysis in suspected pulmonary embolism. BMJ. 2004; 329; 557558.

PubMed: https://www.ncbi.nlm.nih.gov/pmc/articles/PMC516111/

80. Cui JS, Jing ZP, Zhuang SJ, Zhou JW, Zhang W, et al. D-dimer as a biomarker for acute aortic dissection A systematic review and metaanalysis. Medicine. 2015; 94: e471.

PubMed: https://www.ncbi.nlm.nih.gov/pubmed/25634194

81. Lee FY, Chen WK, Chiu CH, Lin CL, $\mathrm{Kao} \mathrm{CH}$, et al. Increased risk of deep vein thrombosis and pulmonary thromboembolism in patients with aortic aneurysms: A nationwide cohort study. PLOS one. 2017; 12: e178587.

PubMed: https://www.ncbi.nlm.nih.gov/pubmed/28591152

82. Leu HS, Yu WC. Massive pulmonary embolism in a patient with Type A Aortic dissection. Clin Cardiol. 2005; 28: 53.

PubMed: https://www.ncbi.nlm.nih.gov/pmc/articles/PMC6654068/

83. Akgul E, Erkul SA, Erkul S, Vural AH. Deep vein thrombosis and pulmonary embolism in a patient with acute type B aortic dissection: a case report. Eur Res J. 2019; 5; 202-205. 
84. M'lodoran, l'lodoran C. High risk pulmonary embolism in a patient with acute dissecting aortic aneurysm. Niger J Clin Pract. 2016; 19: 831-833. PubMed: https://www.ncbi.nlm.nih.gov/pubmed/27811460

85. Ramponi F, Papps T, Edwards J. Successful repair of a concomitant acute Type $A$ aortic dissection and saddle pulmonary embolism. Aorta (Stamford). 2018; 6: 34-36.

PubMed: https://www.ncbi.nlm.nih.gov/pmc/articles/PMC6136673/

86. Chai DZ, Zhang HY, Zhang F. Pulmonary embolism and Stanford Type B aortic dissection in the same patient. J Vascu Med Sur. 2015; 3; 6.

87. Cruz I, Caldera D, Stuart B, Cale R, Joao I, Cotrim C, et al. A case of pulmonary thromboembolism and aortic dissection: The role of echocardiography. Rev Port Cardiol. 2013; 32: 549-550.

PubMed: https://www.ncbi.nlm.nih.gov/pubmed/23731736

88. Prandoni $\mathrm{P}$, Lensing AWA, Prins $\mathrm{MH}$, Ciammaichella $\mathrm{M}$, Perlati $\mathrm{M}$, et al. Prevalence of pulmonary embolism among patients hospitalized for syncope. N Engl J Med. 2016; 375; 1524-1531.

PubMed: https://www.ncbi.nlm.nih.gov/pubmed/27797317

89. Carrascosa MF, Batan AM, Novo MF. Delirium and pulmonary embolism in the elderly. Mayo Clin Proc. 2009; 84: 91-92. https://www. ncbi.nlm.nih.gov/pmc/articles/PMC2664576/

90. Tanislav C, Piulle M, Pabst W, Reichenberger F, Grebe M, et al. High frequency of silent pulmonary embolism in patients with. cryptogenic stroke and patent foramen ovale. Stroke.. 2011; 42: 822-824. PubMed: https://www.ncbi.nlm.nih.gov/pubmed/21257827

91. Sipola P, Hedman M, Jakala P, Karjalainen AM, Peuhkurinen K, et al. Prevalence of pulmonary embolism in patients with suspected cardioembolic ischemic stroke. J Thorac Imaging. 2011; 1: 32-35. PubMed: https://www.ncbi.nlm.nih.gov/pubmed/20489661

92. Abusnina W, Megri M, Edris B, El-Hamdani M. Arterial embolism in a patient with pulmonary embolism and patent foramen ovale. Proc Bayl Univ Med. 2019; 32: 256-258.

PubMed: https://www.ncbi.nlm.nih.gov/pmc/articles/PMC6541092/

93. Belvis R, Masjuan J, Garcia-Barragan N, Cocho D, Marti-Fabregas J, et al. Stroke and pulmonary thromboembolism after a long flight. Eur $\mathrm{J}$ Neurol. 2005; 12: 732-734.

PubMed: https://www.ncbi.nlm.nih.gov/pubmed/16128878

94. Bazan SG, Braga GP, Luvizutto GJ, Trindade AP, Pontes-Neto OM, et al. Bihemispheric paradoxical cerebral embolism in a patient with pulmonary thromboembolism and presumptive fistula right-to-left shunt. J Stroke Cerebrovasc Dis. 2016; 25: e95-e97.

PubMed: https://www.ncbi.nlm.nih.gov/pubmed/27105566

95. Liu M, Menzoian JO. A patient with multiple paradoxical emboli. J Vasc Surg. 2016; 63: 1085-1087.

PubMed: https://www.ncbi.nlm.nih.gov/pubmed/26033010

96. Vyas A, Singh A, Vyas $P$, Kranis $M$, Pacifico $L$, et al. A rare case of simultaneous pulmonary and paradoxical emboli with a thrombus straddling a patent foramen ovale. J Cardiol Cases. 2011: 4: e47-e49. PubMed: https://www.ncbi.nlm.nih.gov/pubmed/30532868

97. Gansera B, Bauer M, Gansera L, Eichinger W. Acute bilatera pulmonary embolism and complete occlusion of the left internal carotid artery caused by paradoxical embolus through a persistent foramen ovale in a 32 year old woman. J Thorac Cardiovasc Surg. 2013; 145 e67-e69.

PubMed: https://www.ncbi.nlm.nih.gov/pubmed/23523034

98. Lapoastolle F, Borron SW, Surget V, Lapandry C, Adnet F. Stroke associated with pulmonary embolism after air travel. Neurology. 2003; 60: 1983-1985.

PubMed: https://www.ncbi.nlm.nih.gov/pubmed/12821746

99. Facciorusso A, Stanisiao M, Pacilli MA, de Luca G, Di Stoifo G, et al. Pulmonary and paradoxical embolism after fracture of the big toe in a patient with patent foramen ovale. J Clin Exper Cardiol. 2012; 3: 12.
100. Almaghraby A, Saleh $\mathrm{Y}$, Hammad B, Abdeinaby M, Kandil AE, et al. A rare case of paradoxical embolism. Interventional Cardiol. 2017; 9 : $43-44$.

101. Mirijello A, D'Errico MM, Curci S, Spatuzza P, Graziano D, et al. Paradoxical embolism with thrombus stuck in a patent foramen ovale: a review of treatment strategies. European Review for Medical and Pharmacological Sciences 2018; 22; 8885-8890.

PubMed: https://www.ncbi.nlm.nih.gov/pubmed/30575931

102. Kumar T, Budnur SC, Mahadevappa NC, Singla V. Paradoxical embolism via a patent foramen ovale. BMJ Case Reports 2013.

103. Cameron SJ, Laskurain E, Holcman K, Richeson JF, Mieszczanska H. Treacherous travellers: Emboli. Am J Med. 2015; 128: 695-698. PubMed: https://www.ncbi.nlm.nih.gov/pubmed/25747190

104. Dada R, Dada J, Abdelsalam M, Agrawal Y. Thrombus straddling a patent foramen ovale, pulmonary embolism and paradoxical embolism: a rare trifecta. BMJ Case Rep. 2018; pii: bcr-2018-227505 PubMed: https://www.ncbi.nlm.nih.gov/pubmed/30337292

105. Miriyala V, Awan MU, Faraj K, Nagra B. Traversing boundaries: thrombus in transit with paradoxical embolism. J Community Hosp Intern Med Perspect. 2016: 6: 31438.

PubMed: https://www.ncbi.nlm.nih.gov/pubmed/27609716

106. Yeh KH, Chang HC. Massive pulmonary embolism with anterolateral ST-segment elevation: electrocardiocardiogram limitations and the role of echocardiogram. Am J Emerg Med. 2008; 26: 632.e1-632.e3. PubMed: https://www.ncbi.nlm.nih.gov/pubmed/18534307

107. ashimoto T, Ando M, Kan T, Fujishima N, Yamasue M, et al. Asthma exacerbation coincident with saddle pulmonary embolism and paradoxical embolism. Tohoku J Ecp Med. 2019; 248: 137-141. PubMed: https://www.ncbi.nlm.nih.gov/pubmed/31243182

108. Morpurgo M, Schmid C, Mandelli V. Factors influencing the clinical diagnosis of pulmonary embolism: Analysis of 229 post mortem cases. Int J Cardiol. 1998; 65(suppl1) s79-S82.

PubMed: https://www.ncbi.nlm.nih.gov/pubmed/9706833

109. Heil J, Miesbach W, Vogl T, Bechstein WO, Reinisch A. Deep vein thrombosis of the upper extremity. Dtsch Arztebl Int. .2017; 114: 244249.

PubMed: https://www.ncbi.nlm.nih.gov/pmc/articles/PMC5415909/

110. De Giorgi A, Fabbian F, Molino C, Tiseo R, Parisi C, et al. Pulmonary embolism and internal jugular vein thrombosis an evocative clues of Lemierre's syndrome: A case report and review of the literature. World J Clin Cases. 2017; 5: 112-118.

PubMed: https://www.ncbi.nlm.nih.gov/pubmed/28352635

111. Tukaye DN, Cavallazzi RS. Paradoxical thromboembolism/STelevation myocardial infarction via a patent foramen ovale in submassive pulmonary embolism following upper extremity deep vein thrombosis: Is it time for a change in the standard of care? Cardiol Res. 2014; 5: 112-117.

PubMed: https://www.ncbi.nlm.nih.gov/pubmed/28348707

112. Gibson NS, Sohne M, Gerdes VEA, Nijkeuter M, Buller HR. The importance of clinical probability assessment in interpreting a normal d-Dimer in patients with suspected pulmonary embolism. Chest. 2008; 134: 789-793.

PubMed: https://www.ncbi.nlm.nih.gov/pubmed/18641091

113. Stein C, Keijsers CJPW, Bootsma JEM, Schouten HJ. Missed diagnosis of pulmonary embolism with age adjusted d-dimer cut-off value. Age Ageing. 2016; 45: 910-91. PubMed: https://www.ncbi.nlm.nih.gov/pubmed/27496940

114. Miniati M, Cenci C, Monti S, Poli D. Clinical presentation of acute pulmonary embolism: Survey of 800 cases. PLoS one. 2012; 7: e30891. PubMed: https://www.ncbi.nlm.nih.gov/pubmed/22383978 